Article

\title{
Application of HPLC-QQQ-MS/MS and New RP-HPLC-DAD System Utilizing the Chaotropic Effect for Determination of Nicotine and Its Major Metabolites Cotinine, and trans-3'-Hydroxycotinine in Human Plasma Samples
}

Jacek Baj ${ }^{1, *(D)}$, Wojciech Flieger ${ }^{1, *(1)}$, Dominika Przygodzka ${ }^{2}$, Grzegorz Buszewicz ${ }^{2}\left({ }^{\circ}\right.$, Grzegorz Teresiński $^{2}(\mathbb{D}$, Magdalena Pizon ${ }^{3}\left[\right.$, Ryszard Maciejewski ${ }^{1}\left[\right.$ and Jolanta Flieger ${ }^{3, *} \mathbb{C}$

check for

updates

Citation: Baj, J.; Flieger, W.;

Przygodzka, D.; Buszewicz, G.;

Teresiński, G.; Pizoń, M.;

Maciejewski, R.; Flieger, J.

Application of HPLC-QQQ-MS/MS

and New RP-HPLC-DAD System

Utilizing the Chaotropic Effect for

Determination of Nicotine and Its

Major Metabolites Cotinine, and

trans-3'-Hydroxycotinine in Human

Plasma Samples. Molecules 2022, 27,

682. https://doi.org/10.3390/

molecules27030682

Academic Editor: Alessandra

Guerrini

Received: 29 December 2021

Accepted: 18 January 2022

Published: 20 January 2022

Publisher's Note: MDPI stays neutral with regard to jurisdictional claims in published maps and institutional affiliations.

Copyright: () 2022 by the authors. Licensee MDPI, Basel, Switzerland. This article is an open access article distributed under the terms and conditions of the Creative Commons Attribution (CC BY) license (https:// creativecommons.org/licenses/by/ $4.0 /)$.
1 Department of Anatomy, Medical University of Lublin, Jaczewskiego 4, 20-090 Lublin, Poland; ryszard.maciejewski@umlub.pl

2 Department of Forensic Medicine, Medical University of Lublin, 20-090 Lublin, Poland; dominikaprzygodzka@umlub.pl (D.P.); g.buszewicz@umlub.pl (G.B.); grzegorz.teresinski@umlub.pl (G.T.)

3 Department of Analytical Chemistry, Medical University of Lublin, Chodźki 4A, 20-093 Lublin, Poland; magdalena.pizon@umlub.pl

* Correspondence: jacek.baj@umlub.pl (J.B.); wwoj24@wp.pl (W.F.); j.flieger@umlub.pl (J.F.); Tel.: +48-81-448-6042 (J.B.); +48-814487194 (J.F.)

\begin{abstract}
The routine techniques currently applied for the determination of nicotine and its major metabolites, cotinine, and trans-3'-hydroxycotinine, in biological fluids, include spectrophotometric, immunoassays, and chromatographic techniques. The aim of this study was to develop, and compare two new chromatographic methods high-performance liquid chromatography coupled to triple quadrupole mass spectrometry (HPLC-QQQ-MS/MS), and RP-HPLC enriched with chaotropic additives, which would allow reliable confirmation of tobacco smoke exposure in toxicological and epidemiological studies. The concentrations of analytes were determined in human plasma as the sample matrix. The methods were compared in terms of the linearity, accuracy, repeatability, detection and quantification limits (LOD and LOQ), and recovery. The obtained validation parameters met the ICH requirements for both proposed procedures. However, the limits of detection (LOD) were much better for HPLC-QQQ-MS/MS $\left(0.07 \mathrm{ng} \mathrm{mL}^{-1}\right.$ for trans-3'-hydroxcotinine; $0.02 \mathrm{ng} \mathrm{mL}^{-1}$ for cotinine; $0.04 \mathrm{ng} \mathrm{mL}^{-1}$ for nicotine) in comparison to the RP-HPLC-DAD enriched with chaotropic additives $\left(1.47 \mathrm{ng} \mathrm{mL}^{-1}\right.$ for trans-3'-hydroxcotinine; $1.59 \mathrm{ng} \mathrm{mL}^{-1}$ for cotinine; $1.50 \mathrm{ng} \mathrm{mL}^{-1}$ for nicotine). The extraction efficiency (\%) was concentration-dependent and ranged between $96.66 \%$ and $99.39 \%$ for RP-HPLC-DAD and $76.8 \%$ to $96.4 \%$ for HPLC-QQQ-MS/MS. The usefulness of the elaborated analytical methods was checked on the example of the analysis of a blood sample taken from a tobacco smoker. The nicotine, cotinine, and trans- $3^{\prime}$-hydroxycotinine contents in the smoker's plasma quantified by the RP-HPLC-DAD method differed from the values measured by the HPLC-QQQ-MS/MS. However, the relative errors of measurements were smaller than $10 \%(6.80 \%$, $6.72 \%, 2.04 \%$ respectively).
\end{abstract}

Keywords: nicotine; cotinine; trans-3'-hydroxycotinine; RP-HPLC-DAD; HPLC-QQQ-MS/MS chaotropic effect

\section{Introduction}

Nicotine is a pyridine chiral alkaloid, most abundant in tobacco leaves (Nicotiana tabacum L.), and in smaller amounts in tomatoes and other plants in the Solanaceae family. Nicotine is known to be a highly addictive neurotoxin [1]. The lethal dose (LD 50 ) value for nicotine is approx. $1-1.5 \mathrm{mg}$ per $\mathrm{kg}$ of body weight. The median $\mathrm{LD}_{50}$ for nicotine is assumed to be $0.8 \mathrm{mg} / \mathrm{kg}$ for adults [2]. The Royal Children's Hospital Melbourne in the 
Clinical Practice Guidelines reports the potentially lethal dose of nicotine for children is greater than $0.5 \mathrm{mg} / \mathrm{kg}$ [3].

The main source of nicotine is tobacco smoke which contains moreover about 5300 chemicals such as carbon monoxide, benzene, hydrogen cyanide, tar, formaldehyde, etc. [4]. For this reason, tobacco smoke is listed as the main cause of cancer in many organs, including the lungs, nose, mouth, pharynx, esophagus, larynx [5]. Tobacco-attributable diseases also include heart diseases, chronic respiratory diseases, and diabetes-all of which may increase the severity of COVID-19 infection. The 2019 WHO report states that almost a third of adults worldwide are regularly exposed to tobacco smoke [6]. In the last years, smoking prevalence among people aged over 15 years has fallen from $22.7 \%$ to $17.5 \%$, however, tobacco is still responsible for one of the causes of more than 8 million premature deaths in the world [7].

Nicotine is perfectly absorbed from cigarette smoke in the alveoli and through the epithelium lining the mouth [8-11]. After getting into the bloodstream, it transforms into an ionized form in about $70 \%$ due to the blood $\mathrm{pH}$ of 7.4 . Only $5 \%$ of nicotine is bound to plasma proteins. The main metabolite of nicotine is cotinine, which is formed as a result of the transformation of about $80 \%$ of inhaled nicotine [10] by the highly genetically variable enzyme CYP2A6 [12]. Due to its long half-life (16-20 h), cotinine is often determined in blood, urine, and saliva as a biomarker of exposure to tobacco smoke $[13,14]$. The main metabolite of cotinine is $3^{\prime}$-hydroxycotinin, detected in the urine and plasma of smokers. However, several other metabolites of cotinine have also been identified in the human body, such as 5-hydroxycotinin, $\mathrm{N}$-cotinine oxide, cotinine methonium ion, glucuronide cotinines, and norcotinine $[10,15]$. Biomarkers of exposure to tobacco smoke are also thiocyanates measured in the saliva of smokers [16].

Various techniques are used to determine the level of nicotine metabolites in body fluids, such as immunoassays e.g., radioimmunoassay (RIA), enzyme-linked immunosorbent assay (ELISA), fluorescence immunoassay (FIA), spectrophotometric, and chromatographic techniques [13,17-21]. The most common methods recognized for the quantification of nicotine and its metabolites are gas (GC) and liquid chromatography (LC) coupled with flame-ionization detection (FID), ultraviolet (UV), and mass spectrometry (MS) detectors. Makoto Yasuda reported an HPLC with fluorometric detection (FD) method for nicotine, cotinine, nicotinic acid, and nicotinamide determination [22]. The authors used the fluorescence of nicotine and cotinine, whereas the remaining two metabolites' fluorescence was enhanced with derivatization using hydrogen peroxide. However, in the described procedure of sample preparation, analytes were extracted from alkalinized human serum via liquid-liquid extraction using hazardous chloroform.

Currently, chromatographic techniques are combined with mass spectrometry, for example liquid chromatography-mass spectrometry (LC-MS) [23-27], liquid chromatographytandem mass spectrometry (LC-MS/MS) [28-30], and gas chromatography-mass spectrometry (GC-MS) [31,32].

So far, the determination of nicotine using LC-MS/MS has been described in various biological matrices, e.g., urine, [33-44], plasma and serum [25,45-48], saliva [37,42,47], and hair [49-53]. The LOD values reported for nicotine are most often in the range $1.00-10.0 \mathrm{ng} \mathrm{mL}^{-1}$. The cotinine was detected on the level of $2 \mathrm{ng} \mathrm{mL}^{-1}$ [25] or, even below $0.1 \mathrm{ng} \mathrm{mL} \mathrm{L}^{-1}$ according to Jacob et al. [26]. An ultra-high-performance liquid chromatography UHPLC/HPLC mixed in tandem with a triple quadrupole system enabled the measurement of serum nicotine with a LOD value of approximately $0.050 \mathrm{ng} \mathrm{mL}^{-1}[54,55]$. In this case, the chromatographic separation was conducted on a reversed-phase column eluted by a linear gradient of mobile phase composed of $0.05 \%$ ammonium hydroxide and acetonitrile. To separate nicotine and its major metabolites, cotinine, trans-3'-hydroxycotinine, nicotine $\mathrm{N}$-oxide and cotinine $\mathrm{N}$-oxide, the hydrophilic interaction chromatography-tandem mass spectrometry (HILIC-MS/MS) was described by Marclay and Saugy [41]. The authors applied the stationary phase of Luna HILIC 200 cross-linked diol with gradient elution mode from $98 \%$ to $35 \%$ acetonitrile in $10 \mathrm{mmol} \mathrm{L}^{-1}$ of ammonium formate buffer at $\mathrm{pH} 3.0$. 
The current study is the first attempt to determine nicotine and its two major metabolites cotinine, and trans-3'-hydroxycotinine by the reverse-phase HPLC system, enriched with chaotropic additives. As predicted previously by Flieger [56-58], the addition of the salts with chaotropic properties has a favorable effect on retention and ensured improved selectivity and efficiency of the reversed-phase chromatographic system towards basic analytes. Nicotine alkaloids as compounds possessing basic functional groups able to ionize require special chromatographic conditions. When they are analyzed by the use of strong acidic mobile phases, unfavorable silanol effects usually provide increase in retention together with the loss of column efficiency.

The aim of the current study is to investigate the usefulness of the classic RP-HPLCDAD system enriched with the addition of a chaotropic salt for the quantitative determination of nicotine, cotinine, and trans-3'-hydroxycotinine in human plasma samples. The method was validated and compared to HPLC-QQQ-MS/MS as a reference. Both methods were compared in terms of the linearity, accuracy, repeatability, recovery as well as detection and quantification limits. Finally, the results of determination of examined analytes in real plasma samples of tobacco smokers were compared and statistically evaluated.

\section{Results}

\subsection{HPLC-DAD of trans-3'-Hydroxycotinine, Cotinine, Nicotine}

All analyzed compounds, i.e., nicotine, cotinine, and trans- $3^{\prime}$-hydroxycotinine, contain nitrogen, which may be in protonated or unprotonated form, depending on the $\mathrm{pH}$ of the reaction medium. Nicotine containing a pyridine ring $\left(\mathrm{p} K_{\mathrm{a}} 2.96\right)$ and a pyrrolidine ring $\left(\mathrm{p} K_{\mathrm{a}}\right.$ 8.07) $[59,60]$ occurs as a diprotonated cation with a charge on both of the ionizable moieties in an acidic aqueous medium. The $\mathrm{p} K_{\mathrm{a}}$ value for both cotinine and trans $-3^{\prime}-$ hydroxycotinine is about 4.5 also due to the protonation of nitrogen on the pyridine ring. Thus, the above analytes exist as the cationic forms in the acidic eluent system ( $\mathrm{pH} 2.7)$. The analytes ionization is a source of strong electrostatic interactions with the counter-anion of the chaotropic salt providing the retention of analytes with distinct hydrophilic properties ( $\log \mathrm{P}$ of nicotine is $0.93, \log \mathrm{P}$ of cotinine is 0.07 , and $\log \mathrm{P}$ of trans- $3^{\prime}$-hydroxycotinin equals -1.45 ) on a hydrophobic RP sorbent. The use of the mobile phase with $\mathrm{pH}$ smaller than 3, has also other advantages in the case of UV detection mode because the protonated forms possess higher absorbance at $260 \mathrm{~nm}$ in comparison to the ones existing at higher $\mathrm{pH}$. Figure 1 presents a chromatogram of a mixture containing trans-3'-hydroxycotinine, cotinine, and nicotine obtained by the use of RP-HPLC-DAD system utilizing sodium hexafluorophosphate as a chaotropic additive to the acidic mobile phase.

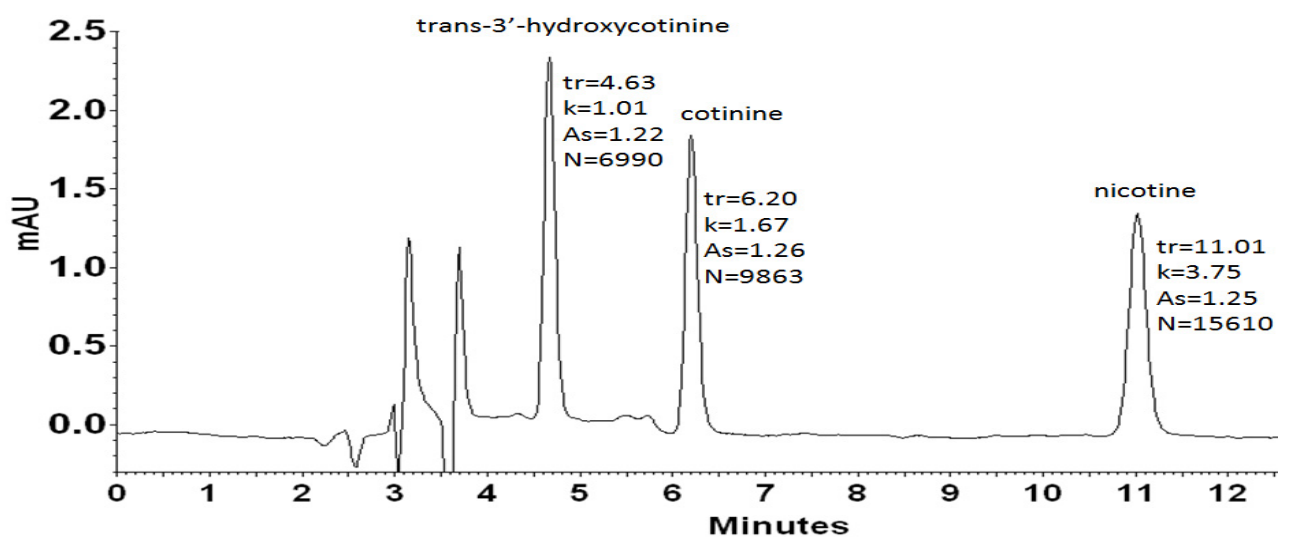

Figure 1. HPLC-DAD chromatogram obtained for solution of standards: trans-3'-hydroxycotinine $(\operatorname{tr}=4.63 \mathrm{~min})$, cotinine $(\operatorname{tr}=6.16 \mathrm{~min})$, nicotine $(\operatorname{tr}=11.01 \mathrm{~min})$ at the concentration level of $500 \mathrm{ng} \mathrm{L}^{-1}$. The analysis was performed using an Agilent 5 HC-C18(2) $(250 \times 4.6 \mathrm{~mm}$ I.D. $)$ column. The mobile phase was acetonitrile $(10 \%, v / v), 20 \mathrm{mM}$ phosphate buffer $\mathrm{pH}=2.7$ containing $30 \mathrm{mM} \mathrm{NaPF}_{6}$ in the whole mobile phase. The DAD detection was set at $260 \mathrm{~nm}$. 
As it can be seen, the applied eluent system permitted complete resolution of the analyzed compounds in an analysis time lower than $15 \mathrm{~min}$. The chaotropic additive ensured satisfactory efficiency expressed in the theoretical plates number $(\mathrm{N})$ in the range of 27,960 to 62,440 , and peak symmetry (As) no more than 1.5 at each case. According to spectra collected for examined compounds (Figure 2) in the range from $220 \mathrm{~nm}$ to $400 \mathrm{~nm}$, the detection wavelength was established at $260 \mathrm{~nm}$. Further optimization experiments were performed at the chosen analytical wavelength.

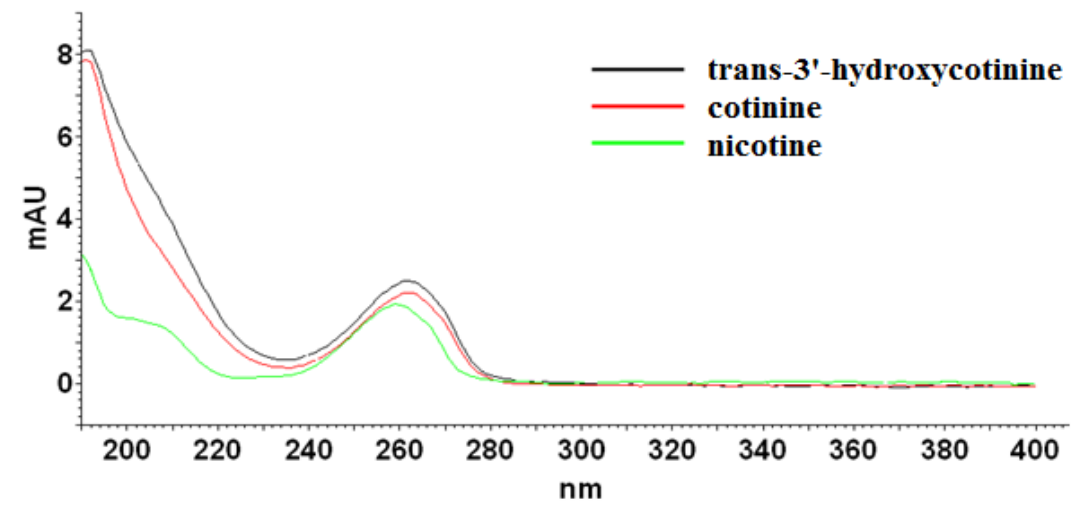

Figure 2. UV-absorption spectra of nicotine, cotinine, and trans-3'-hydroxycotinine standards measured from 220 to $400 \mathrm{~nm}$.

In the case of quantitative analysis, a very important aspect is to achieve the low limits of detection (LOD). A significant reduction in the LOD value can be obtained thanks to the preparation of samples in the mobile phase (Figure 3). As a result, it was possible to reduce the LOD value for nicotine 3.6 times from 6.86 to $\mathrm{LOD}=1.89 \mathrm{ng} \mathrm{mL}^{-1}$. The LOD value for cotinine decreased from 3.88 to $1.77 \mathrm{ng} \mathrm{mL}^{-1}$. The best result was obtained for trans-3'-hydroxycotinine, for which the LOD value was reduced 7.6 times from 11.7 to $1.53 \mathrm{ng} \mathrm{mL}{ }^{-1}$. As can be seen, chaotropic additive provided a higher signal level as well as significantly reduced unwanted noise. Therefore, samples for further quantification were prepared by dilution with the mobile phase.

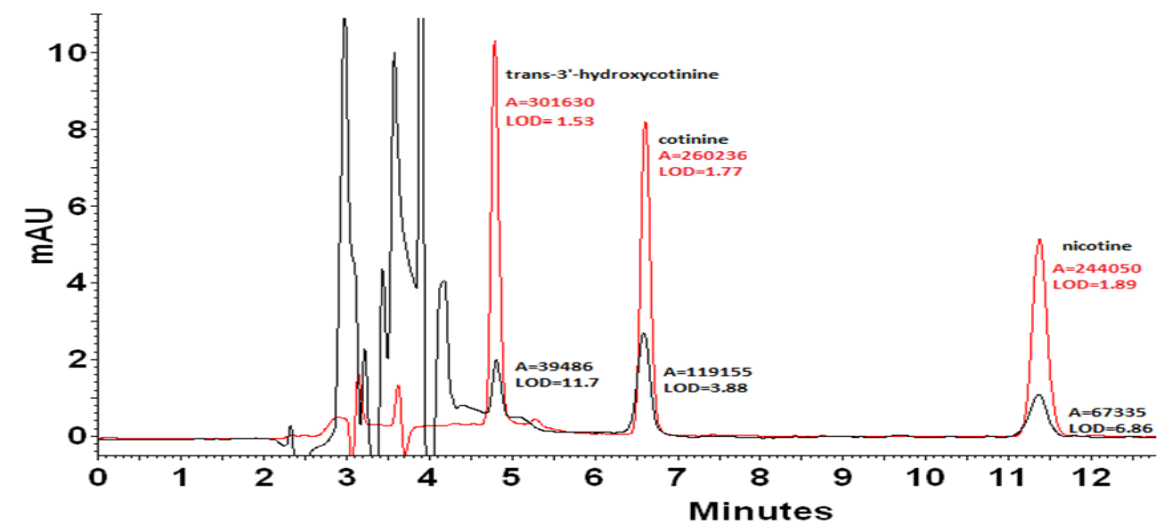

Figure 3. Chromatogram of a mixture of standards with a concentration of $2 \mathrm{mg} \mathrm{mL}^{-1}$ dissolved in methanol (black line) and in the mobile phase (red line). The detection limits [ng $\left.\mathrm{mL}^{-1}\right]$ were estimated considering the analyte concentration that produces a chromatographic peak having a height equal to three times the standard deviation of the baseline noise.

\subsubsection{HPLC-DAD Method Validation}

The matrix effect usually comes from endogenous components coming from the sample or contaminants introduced in the pretreatment process. The matrix effect can be evaluated as the ratio between the slopes of the linear calibration equations of analyte dissolved in the blank matrix per that one obtained for analyte dissolved in the organic 
solvent. In DAD detection mode, the investigated analytes cotinine, nicotine, and trans- $3^{\prime}-$ hydroxycotinine demonstrated a relatively strong matrix effect equaling $86.58 \%, 94.55 \%$, and $83.42 \%$ respectively. In the aim to avoid the influence of the matrix on analytes quantification, the standard addition method (fortification method) ensuring the stability and accuracy of the results was applied in subsequent experiments.

Linearity, LOD and LOQ values were determined for all analytes using an artificial plasma matrix that was spiked with the analytes at seven different concentration levels. The obtained mixtures were further analyzed by the extraction procedure described in the Section 4.2.2. The calibration curves were linear in the range from 10 to $1200 \mathrm{ng} \mathrm{mL}^{-1}$ with the determination coefficients $\left(\mathrm{R}^{2}\right)$ being greater than 0.9980 . The least-squares linear regression analysis was used to determine the statistic parameters which were collected in Table 1.

Table 1. The statistical parameters of the calibration curves $(y=a x+b)$.

\begin{tabular}{|c|c|c|c|c|c|c|c|}
\hline Compound & Slope (a) $\pm \mathbf{s}_{\mathbf{a}}$ & Intercept $(b) \pm s_{b}$ & $\mathbf{R}^{2}$ & se $^{1}$ & $\mathbf{F}^{2}$ & LOD [ng ml ${ }^{-1}$ ] & LLOQ [ng ml-1] \\
\hline trans-3'-hydroksycotinine & $159.47 \pm 3.54$ & $2143.35 \pm 1962.59$ & 0.9980 & 2975.1 & 2024.92 & 1.47 & 4.42 \\
\hline cotinine & $146.14 \pm 2.46$ & $1238.95 \pm 1364.26$ & 0.9989 & 2068.1 & 3519.14 & 1.59 & 4.78 \\
\hline nicotine & $153.49 \pm 3.44$ & $2491.18 \pm 1902.49$ & 0.9980 & 2884.0 & 1996.34 & 1.50 & 4.51 \\
\hline
\end{tabular}

${ }^{1}$ The standard error of estimate (se); ${ }^{2}$ Fisher F statistic.

For recovery and repeatability examination blank plasma matrix was spiked with mixed standard solutions on three concentration levels. Each level was quantified six times to calculate the recovery and relative standard deviation (RSD). Inter- and intra-day precision and accuracy data for nicotine and its metabolites were determined with the LQC (100 ng mL $\left.{ }^{-1}\right), \mathrm{MQC}\left(500 \mathrm{ng} \mathrm{mL}^{-1}\right)$, and HQC (1000 $\left.\mathrm{ng} \mathrm{mL}^{-1}\right)$ samples. Figure 4 presents a representative chromatogram of blank artificial plasma sample and plasma spiked with trans- $3^{\prime}$-hydroxycotinine, cotinine, and nicotine on different concentration levels.

The analytes concentration was calculated from the calibration curve. Recovery (\%) was calculated by comparing the measured analyte concentration to the expected value. Intra-day data were assessed by comparing data from within one run ( $\mathrm{n}=3$ for each QC). Inter-day validation data were obtained from analyses conducted on three subsequent days $(\mathrm{n}=3)$. Accuracy was in the range of $96.66 \%$ to $99.39 \%$. Coefficients of variation (CVs) were $<5 \%$ for intraday precision and $<6 \%$ for interday precision. Obtained results summarized in Table 2 were considered acceptable for all quality samples considering criteria established by the US FDA, that is $85-115 \%$ for accuracy, and $\pm 15 \%$ for precision $[61,62]$.

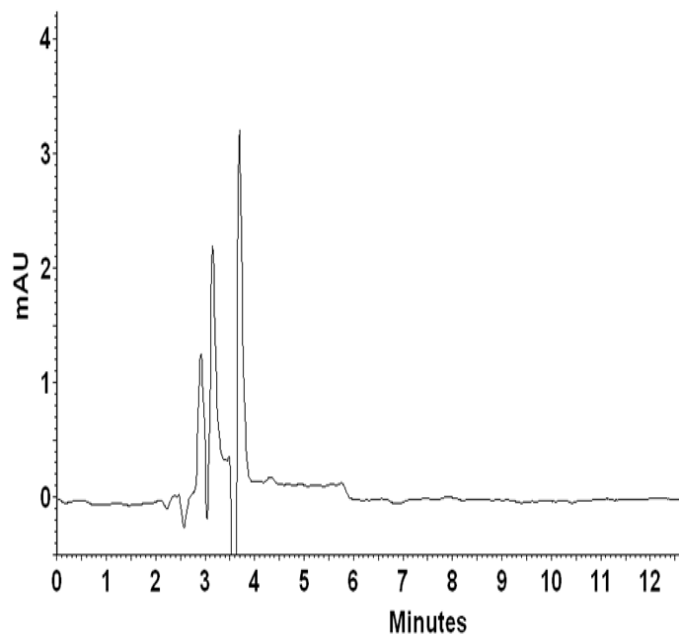

(a)

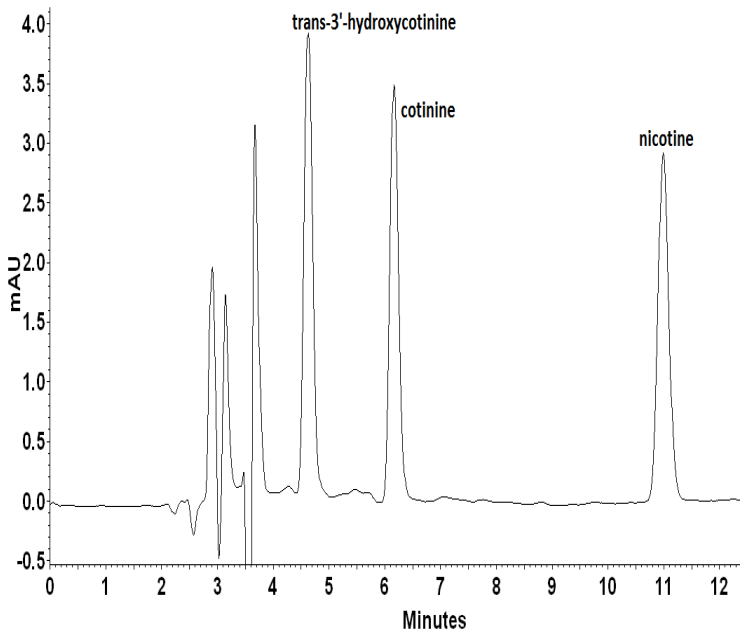

(b)

Figure 4. Cont. 


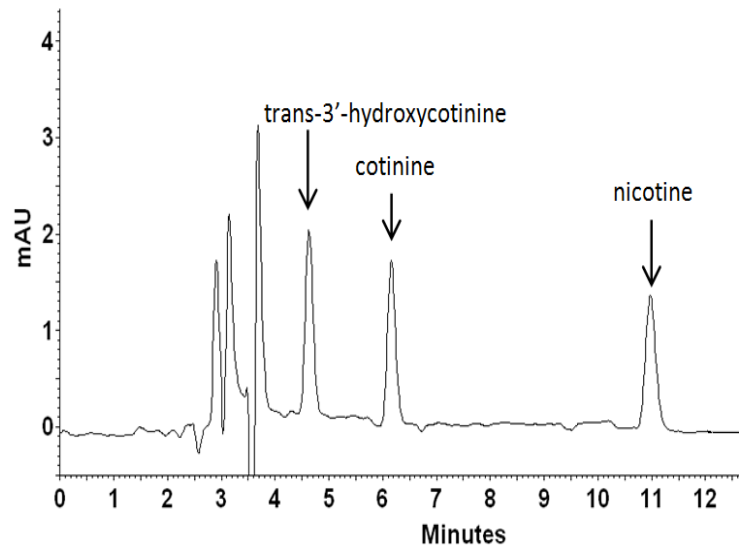

(c)

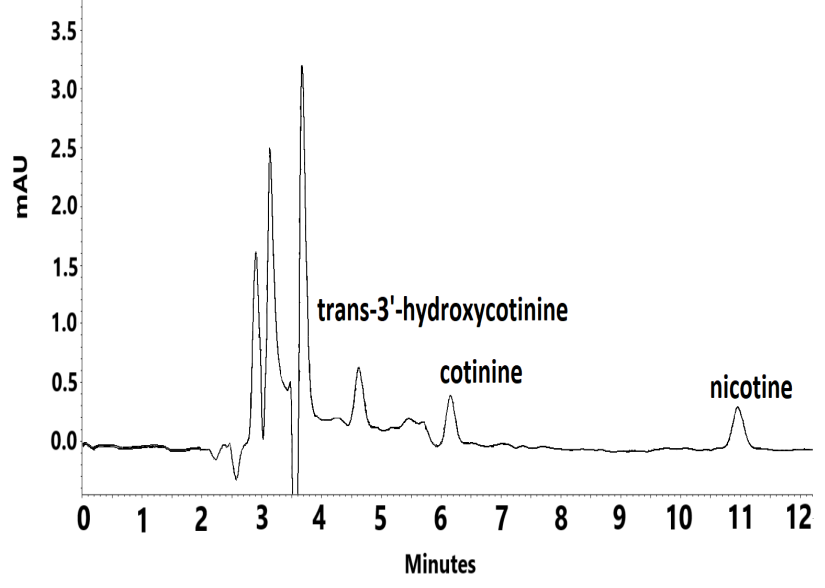

(d)

Figure 4. Representative chromatograms of blank plasma sample (a) and plasma spiked with trans$3^{\prime}$-hydroxycotinine, cotinine, nicotine standards at a concentration of $1000 \mathrm{ng} \mathrm{L}^{-1}$ (b), $500 \mathrm{ng} \mathrm{L}^{-1}$ (c), and $100 \mathrm{ng} \mathrm{L}^{-1}$ (d).

Table 2. The recoveries of trans-3'-hydroxycotinine, cotinine, nicotine from the artificial plasma samples with intra- and inter-day precision.

\begin{tabular}{|c|c|c|c|c|c|}
\hline \multirow[b]{2}{*}{ Compound } & \multirow{2}{*}{$\begin{array}{l}\text { Analyte } \\
\text { Concentration } \\
{\left[n g \mathrm{~mL}^{-1}\right]}\end{array}$} & \multicolumn{2}{|c|}{ Intra Day Precision } & \multicolumn{2}{|c|}{ Inter Day Precision } \\
\hline & & $\begin{array}{c}\text { Extraction Yield } \\
{[\% \pm \mathrm{SD}]}\end{array}$ & $\begin{array}{l}\text { Repeatability } \\
\text { [CV] }\end{array}$ & $\begin{array}{c}\text { Extraction Yield } \\
{[\% \pm \mathrm{SD}]}\end{array}$ & $\begin{array}{c}\text { Repeatability } \\
\text { [CV] }\end{array}$ \\
\hline \multirow{3}{*}{$\begin{array}{c}\text { trans }-3^{\prime}- \\
\text { hydroxcotinine }\end{array}$} & 100 & $96.02 \pm 2.57$ & 2.67 & $87.96 \pm 3.06$ & 3.47 \\
\hline & 500 & $102.22 \pm 0.53$ & 0.52 & $104.61 \pm 2.14$ & 2.04 \\
\hline & 1000 & $100.04 \pm 2.35$ & 2.35 & $101.02 \pm 1.98$ & 1.98 \\
\hline \multirow{3}{*}{ cotinine } & 100 & $93.49 \pm 0.32$ & 0.34 & $97.40 \pm 1.63$ & 1.67 \\
\hline & 500 & $100.03 \pm 1.60$ & 1.59 & $102.93 \pm 2.00$ & 1.95 \\
\hline & 1000 & $98.02 \pm 2.71$ & 2.76 & $100.37 \pm 2.03$ & 2.02 \\
\hline \multirow{3}{*}{ nicotine } & 100 & $100.27 \pm 3.88$ & 3.87 & $112.35 \pm 6.31$ & 5.61 \\
\hline & 500 & $100.68 \pm 2.34$ & 2.32 & $100.60 \pm 0.85$ & 0.85 \\
\hline & 1000 & $97.94 \pm 2.71$ & 2.77 & $94.66 \pm 3.10$ & 3.28 \\
\hline
\end{tabular}

\subsubsection{Analysis of Real Plasma Sample from a Tobacco-Smoking Patient}

The standard additions calibration method was used to determine the concentration of the investigated analytes in a real human plasma sample coming from the tobacco smoker. This method is commonly found when working with clinical, biological, or food samples mainly to avoid the matrix effect and unexpected interferences from matrix components. In a smoker's plasma sample, nicotine and its metabolites were expected at rather low concentration levels. To avoid loss of precision as a result of sample dilution, the supernatant obtained after mixing plasma with an organic solvent was lyophilized and dissolved in a small volume of $300 \mu \mathrm{L}$ of the mobile phase. Obtained results were collected in Table 3.

Table 3. The standard additions calibration method for the determination of nicotine and its major metabolites in plasma of tobacco smoker.

\begin{tabular}{cccccc}
\hline \multirow{2}{*}{ Compound } & \multicolumn{2}{c}{ The Calibration Curve } & \multicolumn{2}{c}{ The Plasma Sample [ng $\mathbf{m L}^{-1}$ ] } \\
\cline { 2 - 7 } & The Linear Equation & $\mathbf{R}^{2}$ & $\begin{array}{c}\text { Conc. in } \\
\text { Sample }\end{array}$ & $\begin{array}{c}\text { Conc. in } \\
\text { Plasma }\end{array}$ & SD \\
\hline Nicotine & $\mathrm{y}=267.70 \mathrm{x}+81,194$ & 0.9882 & 51.02 & 20.92 & 0.61 \\
Cotinine & $\mathrm{y}=132.58 \mathrm{x}+17,314.44$ & 0.9999 & 130.62 & 53.55 & 1.48 \\
trans-3'-hydroksycotinine & $\mathrm{y}=191.96 \mathrm{x}+3427.33$ & 0.9817 & 17.85 & 7.39 & 0.08 \\
\hline
\end{tabular}




\subsection{HPLC-QQQ-MS/MS of trans-3'-Hydroxycotinine, Cotinine, Nicotine}

When standards and deuterated internal standards were added to the blank plasma sample, all analytes showed clear well-defined peaks without any interferences. The intensities of the peaks were above 200-times higher in comparison to the background signals detected for the blank plasma samples (Figure 5). HPLC-QQQ-MS/MS chromatograms of nicotine and examined metabolites are collected in Figure 6.

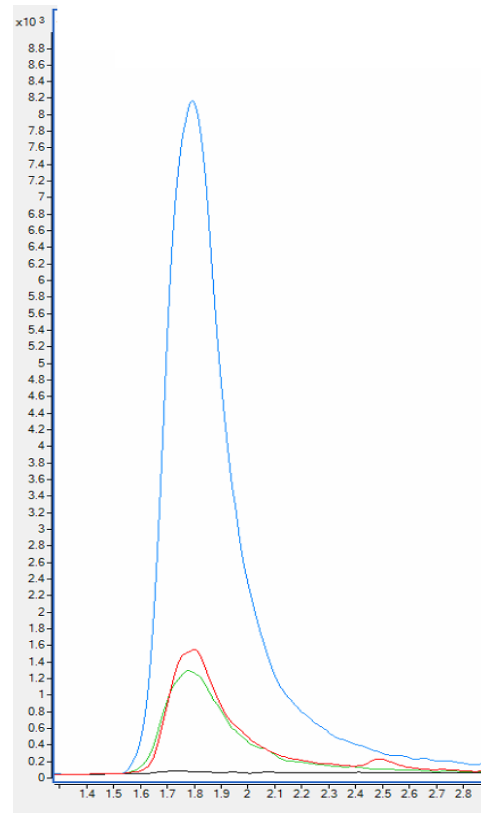

$163 \rightarrow 117$

(a)

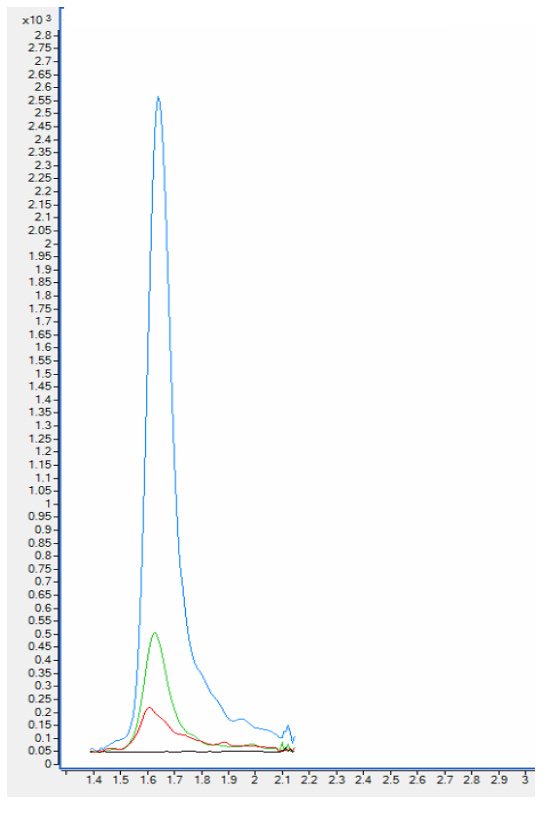

$193 \rightarrow 80$

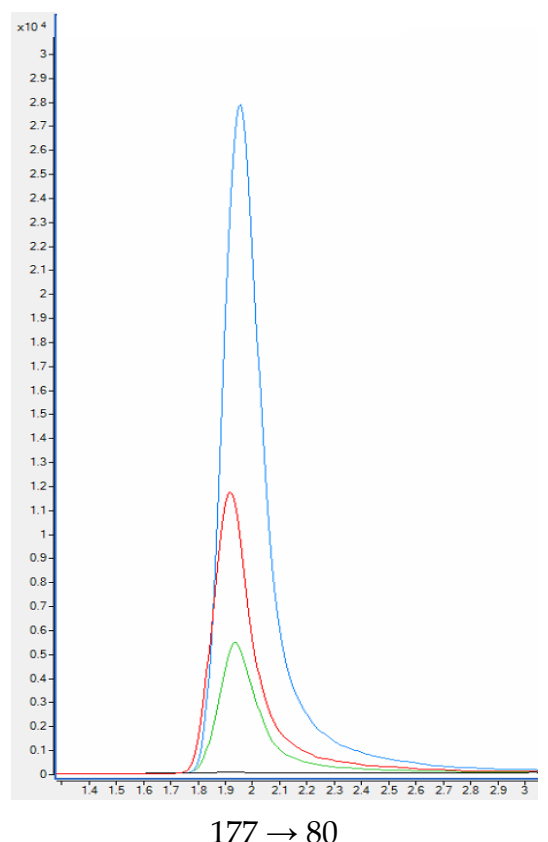

(b)

(c)

Figure 5. HPLC-QQQ-MS/MS chromatograms of quantitative transition of nicotine (a) and metabolites: cotinine (b), trans-3'-hydroksycotinine (c) from the blank plasma sample, plasma samples used in the validation process and smoker' plasma sample. Plasma sample spiked with $100 \mathrm{ng} \mathrm{mL}^{-1}$ of analytes (blue); Plasma sample spiked with $20 \mathrm{ng} \mathrm{mL}^{-1}$ of analytes (green); smoker' plasma sample (red); blank plasma sample (black). 


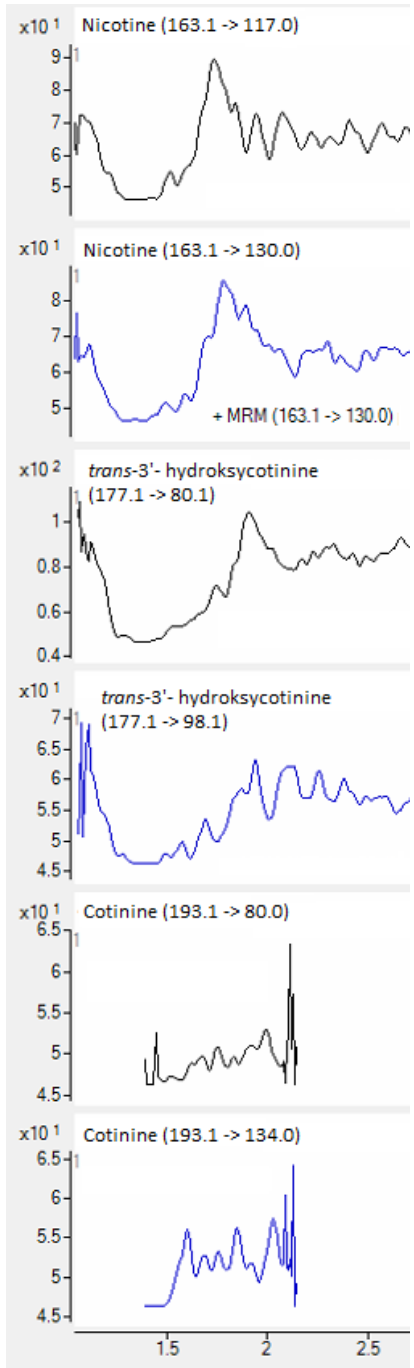

(a)

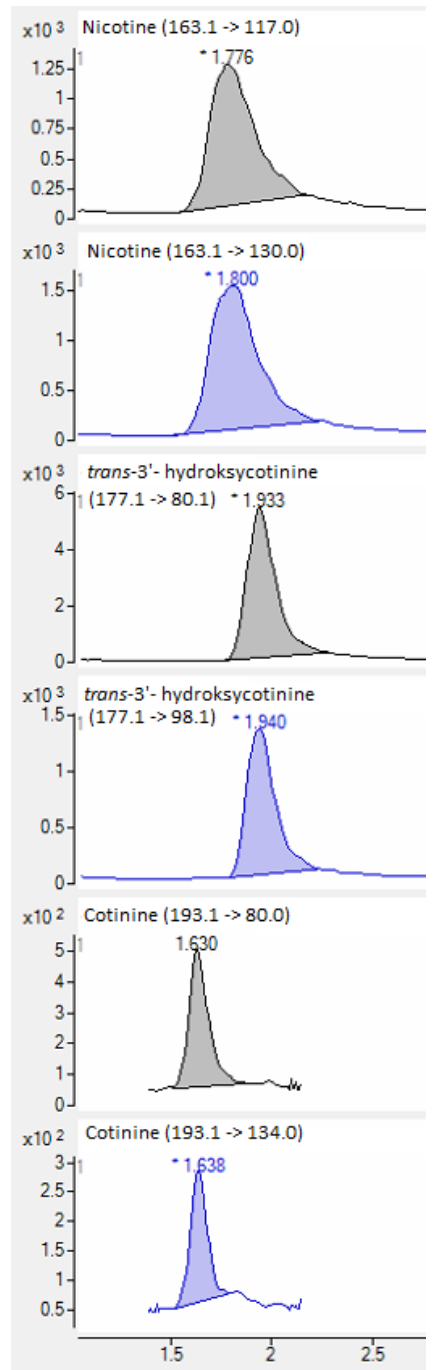

(b)

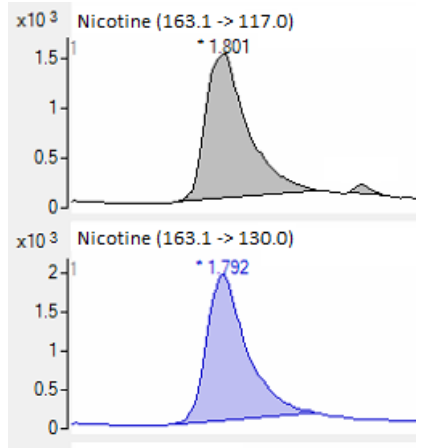

$\times 104$ trans-3'- hydroksycotinine

$1.25-1$ (177.1 -> 80.1) • 1.916

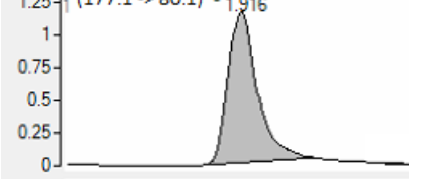

x10 3 trans-3'- hydroksycotinine

$3-1(177.1 \rightarrow 98.1) \cdot 1.215$

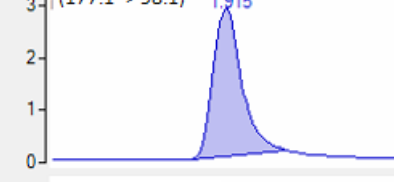

$\times 10^{2}$ Cotinine $(193.1 \rightarrow 80.0)$

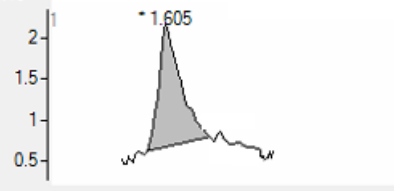

$\times 10^{2}$ Cotinine $(193.1 \rightarrow 134.0)$

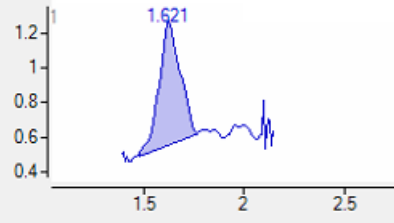

(c)

Figure 6. HPLC-QQQ-MS/MS chromatograms of quantitative (black) and confirmatory (blue) transitions of nicotine and metabolites from the blank plasma sample (a), plasma samples used in the validation process $(\mathbf{b})$, and smoker' plasma sample (c).

\section{Validation of HPLC-QQQ-MS/MS}

Nicotine and its metabolites calibration curves were prepared in the range 2.0 to $200 \mathrm{ng} \mathrm{mL}^{-1}$. Calibration curve parameters were collected in Table 4 . For each of the compounds tested, the curves had an $\mathrm{R}^{2}$ above 0.999 (only for nicotine it was 0.9989). Smoker's plasma samples were analyzed together with two QC samples (20 and $\left.200 \mathrm{ng} \mathrm{mL}^{-1}\right)$.

Table 4. The statistical parameters of the calibration curves $(y=a x+b)$.

\begin{tabular}{cccccc}
\hline Compound & Slope (a) & Intercept (b) & $\mathbf{R}^{\mathbf{2}}$ & $\begin{array}{c}\text { LOD } \\
\text { [ng } \mathbf{~ m}^{-\mathbf{1}} \text { ] }\end{array}$ & $\begin{array}{c}\text { LOQ } \\
\text { [ng } \mathbf{~ m}^{-\mathbf{1}} \text { ] }\end{array}$ \\
\hline trans-3'-hydroksycotinine & 0.004926 & -0.003564 & 0.9990 & 0.07 & 0.15 \\
cotinine & 0.082795 & 0.017080 & 0.9990 & 0.02 & 0.06 \\
nicotine & 0.035986 & -0.061937 & 0.9989 & 0.04 & 0.10 \\
\hline
\end{tabular}

The recovery study was performed for each analyte at two concentration levels of 20 and $200 \mathrm{ng} \mathrm{mL} \mathrm{mL}^{-1}$. As can be seen in Table 5, the recovery of analytes was concentrationdependent. For the smaller concentration of $20 \mathrm{ng} \mathrm{mL}^{-1}$ the percentage of recovery was in the range from $76.8 \%$ to $81.9 \%$, whereas for ten times higher concentration levels, the 
recovery was between 93.1 and $96.4 \%$. In a typical smoker's plasma sample, the investigated analytes were detected on the level of $7.544,50.180,19.588 \mathrm{ng} \mathrm{mL}^{-1}$ for trans-3'-hydroxycotinine, cotinine, nicotine respectively by HPLC-QQQ-MS/MS.

Table 5. Recovery and precision of the investigated analytes quantification evaluated by HPLC-QQQMS/MS.

\begin{tabular}{|c|c|c|c|c|c|c|}
\hline \multirow{2}{*}{ Analyte } & \multirow{2}{*}{$\begin{array}{c}\text { Analyte } \\
\text { Concentration } \\
{[\mathrm{ng} \mathrm{ml}-1]}\end{array}$} & \multirow{2}{*}{ Recovery \% } & \multirow{2}{*}{$\begin{array}{c}\text { Intra Day } \\
\text { Precision } \\
\text { CV\% }\end{array}$} & \multirow{2}{*}{$\begin{array}{l}\text { Inter Day } \\
\text { Precision } \\
\text { CV\% }\end{array}$} & \multicolumn{2}{|c|}{$\begin{array}{c}\text { Smoker's Plasma } \\
\text { Sample }\end{array}$} \\
\hline & & & & & $\begin{array}{c}\text { Conc. } \\
{\left[\mathrm{ng} \mathrm{mL}^{-1}\right]}\end{array}$ & SD \\
\hline trans-3'- & 20 & $81.9 \%$ & $2.9 \%$ & $4.6 \%$ & \multirow{2}{*}{7.544} & \multirow{2}{*}{0.714} \\
\hline hydroxycotinine & 200 & $96.4 \%$ & $1.4 \%$ & $5.6 \%$ & & \\
\hline \multirow{2}{*}{ cotinine } & 20 & $83.2 \%$ & $1.3 \%$ & $5.1 \%$ & \multirow{2}{*}{50.180} & \multirow{2}{*}{0.551} \\
\hline & 200 & $94.8 \%$ & $1.3 \%$ & $4.5 \%$ & & \\
\hline \multirow{2}{*}{ nicotine } & 20 & $76.8 \%$ & $2.1 \%$ & $5.7 \%$ & \multirow{2}{*}{19.588} & \multirow{2}{*}{0.001} \\
\hline & 200 & $93.1 \%$ & $1.8 \%$ & $6.6 \%$ & & \\
\hline
\end{tabular}

\subsection{Comparison of the Results Obtained by RP-HPLC-DAD with HPLC-QQQ-MS/MS}

The nicotine, cotinine, and trans-3'-hydroxycotinine contents in the smoker's plasma quantified by the RP-HPLC-DAD method differ from the values measured by the HPLCQQQ-MS/MS. The relative error values were $6.80 \%, 6.72 \%, 2.04 \%$, respectively. It should be noted, however, that the marked quantities are of the same order of magnitude. To statistically compare the series of measurements, linear regression analysis or a Bland-Altman plot (B \& $\mathrm{A}$ is known as the Tukey mean difference plot) could be used. It could be possible in the case of much more samples from smokers. Unfortunately, blood collection is an invasive procedure, so in the future, the applicability of the method should be checked on other biological matrices, such as urine or saliva. The results were compared utilizing a statistical significance $t$-test. The results obtained for analysis of trans-3'-hydroxycotinine, cotinine and nicotine in plasma samples using HPLC-DAD and HPLC-QQQ-MS/MS showed that there are no significant differences between these two chromatographic techniques using the $t$-test at a significance level of 0.05 on a two-tailed test for 2 degrees of freedom.

\section{Discussion}

The presence of nicotine metabolites in body fluids can be confirmed by various techniques, differing in implementation costs, time consumption, selectivity, reliability and efficiency. Despite the availability of a wide range of analytical tools, the most technologically advanced ones are not standard laboratory equipment, and their operation is too expensive to be used for epidemiological, toxicological and even clinical screening, which prefer quick and cheap analytical techniques.

Our study concerns a new method for the determination of nicotine, cotinine and trans3'-hydroxycotinin in the blood plasma, using the classic RP-HPLC-DAD system modified with the addition of $\mathrm{NaPF}_{6}$ chaotropic salt at millimolar concentration. The obtained results regarding the selectivity of the separation exceed the previous HPLC separations, which have been described in the literature so far. The addition of a chaotropic salt had a positive effect on the achieved detection and quantification limits. It is known, however, that HPLC-DAD cannot compete with tandem mass spectrometry, which allows for unique identification of compounds and provides the best possible sensitivity of the method. It should be emphasized, that the obtained limit of quantification (LLOQ) for cotinine was even smaller than $10 \mathrm{ng} \mathrm{mL} \mathrm{mL}^{-1}$. This value is sufficient for selecting smokers, because according to Kim [63] the serum cotinine cutoff value range of 10-20 ng/mL, serving as a cut-off point to verify patients according to their tobacco status.

Our study confirmed the advantage of chaotropic additives in RP systems over gradient analysis or multi-component eluents in order to ensure appropriate selectivity and sensitivity. Comparing the new RP-HPLC method with the previous ones, there is a 
noticeable difference in the achieved limits of detection and quantification. In the developed method, the detection limit for nicotine, cotinine and trans-3'-hydroxycotinin is $1.50 \mathrm{ng} \mathrm{mL}^{-1}, 1.59 \mathrm{ng} \mathrm{mL}^{-1}$ and $1.47 \mathrm{ng} \mathrm{mL}^{-1}$, respectively. Using HPLC-QQQ-MS/MS, the LOD values were even more spectacular achieving the levels of $0.04,0.02,0.07 \mathrm{ng} \mathrm{mL}^{-1}$ respectively. Miller et al. [38] reported a similar detection limit of $1 \mathrm{ng} / \mathrm{mL}$ for all analytes for LC-MS/MS with electrospray ionization (ESI) using multiple reaction monitoring (MRM). Whereas McGuffey et al. [40] reported the detection limits of 1.94, 1.55, 3.53 ng/mL for trans-3'-hydroxycotinine, nicotine, cotinine respectively in LC-MS/MS measurements. Usually, the limit of quantification achieved by LC-MS/MS are smaller like $0.36,0.32 \mathrm{ng} / \mathrm{mL}$ for nicotine, cotinine, respectively [45]. Zuccaro et al. [21] described the HPLC-DAD method that provided the limit of detection for nicotine, cotinine and trans-3'-hydroxycotinin of 10,5 , and $5 \mathrm{ng} \mathrm{mL}^{-1}$, respectively. The method used a time-consuming gradient elution, which allowed the separation of the analytes in more than $20 \mathrm{~min}$. Another advantage of our method is the possibility of isocratic elution in no more than $15 \mathrm{~min}$. While most authors using MS detection, despite its exceptional sensitivity, use the gradient elution mode $[26-30,33,34,38,40,46,47]$. Until now, only a few papers reported the usefulness of the isocratic elution mode $[25,37,39]$.

The high convergence of the results (the relative error $<10 \%$ ) obtained with the new method and the reference one in the test carried out on a tobacco smoker, as well as the satisfactory validation parameters prove the success of the new method in confirming and quantifying the exposure to nicotine and its metabolites. The new method can be an alternative tool in applications that prefer fast, cheap, reliable methods using standard laboratory equipment.

\section{Materials and Methods}

\subsection{Standards and Reagents}

Standards of (-)-nicotine, (-)-cotinine, trans-3'-hydroxcotinine, caffeine were purchased from Sigma-Aldrich (St. Louis, MO, US). Deuterated $( \pm)$-nicotine-d4, and $( \pm)$ cotinine-d3 standards were purchased from Merck (Darmstadt, Germany). Sodium hexafluorophosphate $\left(\mathrm{NaPF}_{6}\right)$, ammonium formate $\left(\mathrm{HCOONH}_{4}\right)$ eluent additive for LC-MS, LiChropur $^{\mathrm{TM}}, \geq 99.0 \%$, formic acid (HCOOH) $98-100 \%$ for LC-MS LiChropur ${ }^{\mathrm{TM}}$ were obtained from Sigma-Aldrich. $85 \% \mathrm{~m} / \mathrm{m}$ phosphoric acid $\left(\mathrm{H}_{3} \mathrm{PO}_{4}\right)$, and sodium hydroxide $(\mathrm{NaOH})$ were obtained from POCH (Gliwice, Poland). Plasma Control was obtained from Recipe chemicals (München, Germany). Acetonitrile $\left(\mathrm{ACN}, \mathrm{C}_{2} \mathrm{H}_{3} \mathrm{~N}\right)$ and methanol $(\mathrm{MeOH}$, $\mathrm{CH}_{3} \mathrm{OH}$ ) of HPLC reagent grade were obtained from Merck (Darmstadt, Germany). Water purified by ULTRAPURE Millipore Direct-Q 3UV-R (Merck, Darmstadt, Germany) of the resistivity $18.2 \mathrm{M} \Omega \mathrm{cm}$ was used to prepare the aqueous solutions.

\subsection{RP-HPLC-DAD Enriched with Chaotropic Salt}

The HPLC analysis was carried out using Elite LaChrom HPLC Merck-Hitachi (Merck, Darmstadt, Germany), equipped with a DAD detector (L-2455), column thermostat Jetstream 2 Plus $\left(100,375\right.$, Knauer). Chromatographic separation was conducted at $30^{\circ} \mathrm{C}$ on a reversed-phase column Agilent $5 \mathrm{HC}-\mathrm{C} 18(2)(250 \times 4.6 \mathrm{~mm}$ I.D., $5 \mu \mathrm{m}, 180 \mathrm{~A}$, Agilent Technologies, Santa Clara, CA, US). The mobile phase composed of $10 \%(v / v)$ acetonitrile in phosphate buffer was pumped through the chromatographic system at a flow rate of $1.0 \mathrm{~mL} \mathrm{~min}^{-1}$. The buffer concentration was $20 \mathrm{mM}$, whereas chaotropic salt concentration was $30 \mathrm{mM}$ in the whole mobile phase. The initial buffer solution $(0.1 \mathrm{M})$ was prepared by dissolving $0.5 \mathrm{~mL} 85 \%(\mathrm{~m} / \mathrm{m})$ orthophosphoric acid in $80 \mathrm{~mL}$ water and adjusting to $\mathrm{pH}=2.7$ with saturated sodium hydroxide solution. The $\mathrm{pH}$ values were measured with CPC-105 Elmetron pH-meter (Zabrze, Poland). The mobile phases were filtered with a Nylon 66 membrane filter (Merck, Darmstadt, Germany) with pore size $0.45 \mu \mathrm{m}$. The injection volume was $20 \mu \mathrm{L}$ corresponding to the volume of the Rheodyne injector loop. The diode array detector was operated at $260 \mathrm{~nm}$. 


\subsubsection{Preparation of Stocks and Working Standard Solutions}

Individual stock solutions of nicotine and its metabolites were prepared in methanol and stored at $-20^{\circ} \mathrm{C}$. The calibration curve standards of each analyte at seven concentration levels in the range of 10.00 to $1200.00 \mathrm{ng} \mathrm{mL}^{-1}\left(10,50,200,400,700,900,1200 \mathrm{ng} \mathrm{L}^{-1}\right)$ were prepared by serial dilution of the $20 \mu \mathrm{g} \mathrm{mL}^{-1}$ stock solutions with the mobile phase. Working solutions were prepared also for quality control samples (QCs) by dilutions of stock solution to obtain a final concentration of $100,500,1000 \mathrm{ng} \mathrm{L}^{-1}$.

\subsubsection{The Recovery Study}

The calibration curves were constructed by plotting the standard peak area versus the concentrations spiked in the blank artificial plasma matrix. A total $0.01 \mathrm{~mL}$ of artificial plasma matrix, which was free from nicotine metabolites were spiked with $0.05 \mathrm{~mL}$ of the appropriate standard solution. Then, $140 \mu \mathrm{L}$ acetonitrile was added to each mixture, vortex $60 \mathrm{~s}$ and centrifuged at $9000 \times g$ for $30 \mathrm{~min}$. The supernatant of each aliquot of plasma was diluted to $1 \mathrm{~mL}$ with the mobile phase. A $20 \mu \mathrm{L}$ of the extract was injected directly into the HPLC column. The statistical parameters of the curve were estimated using linear regression analysis. The LOD and LOQ were derived via signal-to-noise ratio (SN). The LOQ is 10 times the standard deviation $(\sigma)$ of the blank whereas the LOD is related to $3 \sigma$. Recoveries and stability were examined using blank samples fortified with three different levels of 100,500 , and $1000 \mathrm{ng} \mathrm{L}^{-1}$. Samples of each level were prepared in six replicates. The relative standard deviation (RSD) values represent the variability and repeatability of the method.

\subsubsection{Preparation of the Plasma Samples from the Smoker}

Human plasma samples were collected by venipuncture (approximately $10 \mathrm{~mL}$ of whole blood) from a healthy volunteer who gave informed consent, 15 min after smoking the cigarette. The sample was immediately centrifuged at $870 \mathrm{~g}$ for $10 \mathrm{~min}$ to obtain plasma. The plasma from the smoker was analyzed maintaining the fixed plasma to acetonitrile ratio (1:14). To $1.45 \mathrm{~mL}$ of plasma, $20 \mathrm{~mL}$ of acetonitrile was added, then vortex $10 \mathrm{~min}$ and centrifuged at $9000 \times g$ for $30 \mathrm{~min}$. The obtained supernatant was lyophilized with freeze dryer Christ ALPHA 2-4 LD plus from Millrock Technology (Kingston, NY, USA), and the dry residue was dissolved in $300 \mu \mathrm{L}$ of the mobile phase. The solution was divided into five vials, each with $50 \mu \mathrm{L}$. Then the samples were spiked with the same volume $(50 \mu \mathrm{L})$ of the mixture containing increasing concentration of the analytes giving finally concentration of $10,50,100,300$, and $500 \mathrm{ng} \mathrm{mL}^{-1}$. The samples of $20 \mu \mathrm{L}$ were injected directly into the HPLC column. The calibration curves of this new data set showed linear relationships between the analyte concentrations versus the peak areas measured at $260 \mathrm{~nm}$ of wavelength. The concentration of the analyte was determined by extrapolating the line to the $x$-axis of the calibration curve. The final results were calculated considering the dilution $(2 \times)$ and concentrating steps $(4.83 \times)$.

\subsection{HPLC-QQQ-MS/MS}

\subsubsection{Apparatus and Detection Conditions}

The LC-MS analysis was carried out using a triple quadrupole system (HPLC 1260 Agilent Technologies, Germany coupled to triple quadrupole mass spectrometer QqQ 6460, Agilent Technologies, USA) equipped with electron spray ionization (ESI) source. The chromatographic separations were performed using a ZORBAX RRHD StableBond C18 column $2.1 \times 150 \mathrm{~mm}, 1.8 \mu \mathrm{m}$, (Agilent Technologies, USA). The column was heated to $50{ }^{\circ} \mathrm{C}$. The analytes were eluted using a mobile phase consisting of $40 \%(v / v)$ acetonitrile in $5 \mathrm{mM}$ ammonium formate $(\mathrm{pH} 4.5)$ in water pumped at a flow-rate of $300 \mu \mathrm{L} \mathrm{min}{ }^{-1}$. The injection volume was $2 \mu \mathrm{L}$. The run time for HPLC-MS/MS method was $3.5 \mathrm{~min}$. Mass spectrometric data were collected in positive ion mode, using multiple reaction monitoring mode. The ESI-MS/MS parameters and the retention time for the tested compounds are presented in Table 6. 
Table 6. ESI-MS/MS parameters and retention time for selected compounds.

\begin{tabular}{|c|c|c|c|c|c|c|}
\hline Compounds & $\begin{array}{l}\text { Precursor } \\
\text { Ion }[\mathrm{m} / \mathrm{z}]\end{array}$ & $\begin{array}{l}\text { Product Ion } \\
{[\mathrm{m} / \mathrm{z}]}\end{array}$ & $\begin{array}{c}\text { Fragmentor } \\
{[\mathrm{V}]}\end{array}$ & $\begin{array}{l}\text { Collision } \\
\text { Energy [V] }\end{array}$ & Polarity & $\begin{array}{l}\text { Retention } \\
\text { Time [min.] }\end{array}$ \\
\hline $\begin{array}{c}\text { trans- } 3^{\prime}- \\
\text { hydroxcotinine }\end{array}$ & 193 & $\begin{array}{c}134 \\
80\end{array}$ & 144 & $\begin{array}{l}20 \\
28\end{array}$ & Positive & 1.77 \\
\hline cotinine & 177 & $\begin{array}{l}98 \\
80\end{array}$ & 144 & $\begin{array}{l}20 \\
28\end{array}$ & Positive & 2.13 \\
\hline cotinine-d3 & 180 & $\begin{array}{c}101 \\
80\end{array}$ & 116 & $\begin{array}{l}24 \\
28\end{array}$ & Positive & 2.13 \\
\hline nicotine & 163 & $\begin{array}{l}130 \\
117\end{array}$ & 116 & $\begin{array}{l}20 \\
28\end{array}$ & Positive & 1.79 \\
\hline nicotine-d4 & 167 & $\begin{array}{l}136 \\
134\end{array}$ & 116 & $\begin{array}{l}16 \\
20\end{array}$ & Positive & 1.80 \\
\hline
\end{tabular}

\subsubsection{The Calibration Curve Preparation for the MS/MS Method}

Calibration curve was prepared using plasma without nicotine and its metabolites. To $45 \mu \mathrm{L}$ of clear plasma was added $5 \mu \mathrm{L}$ of methanol solution of nicotine and its metabolites in proper concentration (to obtain levels 2, 5, 10, 20, 100 and $200 \mathrm{ng} \mathrm{mL}^{-1}$ ). Then was added $5 \mu \mathrm{L}$ of deuterated internal standards (IS), i.e., nicotine-D4 and cotinine-D3 at a concentration of $100 \mathrm{ng} \mathrm{mL}^{-1}$ in $\mathrm{MeOH}$. Samples were precipitated with $500 \mu \mathrm{L}$ of frozen acetonitrile containing $0.1 \% \mathrm{HCOOH}$. The sample was centrifuged $2 \mathrm{~min}$ at 14,000 rpm, then the $500 \mu \mathrm{L}$ supernatant was transferred to an Eppendorf vial $(2 \mathrm{~mL})$. It was evaporated to dryness under a stream of $\mathrm{N}_{2}$ at $40{ }^{\circ} \mathrm{C}$ (using a RapidVap ${ }^{\circledR} \mathrm{N}_{2} / 48$ rotary evaporator, Labconco, Kansas City, MO, USA). The dry residue was dissolved in $50 \mu \mathrm{L}$ of the eluent and centrifuged for $2 \mathrm{~min}$ (at 14,000 rpm). The extracts were transferred to the inserts and analyzed with the HPLC-QQQ-MS/MS system.

\subsubsection{Method Validation}

Quantitative analysis was performed using a calibration curve in the range of 2-200 ng mL ${ }^{-1}$. In order to validate the method, six replications were performed for each of the calculated parameters (repeatability and recovery) at two concentration levels. Determination of LODs (limits of detection) and LOQs (limit of quantification) was based on the calibration curve. The LOD values were calculated as $3 \times \sigma / S$ where $S$ is the slope of the calibration curve and $\sigma$ is the standard deviation of the response, while the LOQ was calculated as $10 \times \sigma / \mathrm{S}$.

\subsubsection{Sample Preparation}

A total $50 \mu \mathrm{L}$ of test plasma and $5 \mu \mathrm{L}$ of deuterated internal standards (IS), i.e., nicotineD4 and cotinine-D3 at a concentration of $100 \mathrm{ng} \mathrm{mL}^{-1}$ in $\mathrm{MeOH}$, were added to a $2 \mathrm{~mL}$ test tube. Plasma with IS supplement was mixed and precipitated by adding $500 \mu \mathrm{L}$ of frozen acetonitrile containing $0.1 \% \mathrm{HCOOH}$. The sample was centrifuged for 2 min at $14,000 \mathrm{rpm}$, then the $500 \mu \mathrm{L}$ supernatant was transferred to an Eppendorf vial ( $2 \mathrm{~mL})$. It was evaporated to dryness under a stream of $\mathrm{N}_{2}$ at $40{ }^{\circ} \mathrm{C}$ (using a RapidVap ${ }^{\circledR} \mathrm{N}_{2} / 48$ rotary evaporator). The dry residue was dissolved in $50 \mu \mathrm{L}$ of the eluent and centrifuged for $2 \mathrm{~min}$ (at 14,000 rpm). The extracts were transferred to the inserts and analyzed with the HPLC-QQQ-MS/MS system.

\section{Conclusions}

The paper compares two methods used for the determination of nicotine and its metabolites in human blood plasma, i.e., HPLC-QQQ-MS/MS and RP-HPLC-DAD enriched with the addition of chaotropic salt. Both methods met the validation criteria for the determination of xenobiotics in biological matrices regarding linearity, accuracy, repeatability, detection, and quantification limits. It should be emphasized that our work presents, for the first time, a reversed-phase HPLC chromatographic system enriched with chaotropic additives, for this purpose. RP-HPLC-DAD belongs to classic techniques, which are widely applied in analytical laboratories. We have proven that it can be easily adapted 
to study nicotine metabolites. Despite, the quantification limits of the HPLC-QQQ-MS/MS method being characterized by several times lower values, the developed chaotropic RPHPLC-DAD method appears to be sufficient for toxicological and epidemiological studies of selecting patients exposed to tobacco smoke.

Author Contributions: Conceptualization, J.F. and J.B.; methodology, D.P., G.B.; software, G.T., G.B., J.B.; validation, D.P., M.P. and W.F.; formal analysis, D.P., M.P.; investigation, D.P., M.P.; resources, R.M.; data curation, R.M., W.F.; writing-original draft preparation, J.F.; writing-review and editing, J.F.; visualization, M.P., D.P.; supervision, G.T.; project administration, G.T.; funding acquisition, G.T. All authors have read and agreed to the published version of the manuscript.

Funding: This research received no external funding.

Institutional Review Board Statement: All subjects gave their informed consent for inclusion before they participated in the study. The study was conducted in accordance with the Declaration of Helsinki, and the protocol was approved by the the Local Bioethical Committee of the Medical University of Lublin (approval no KE-0254/181/2021; 27-05-2021).

Informed Consent Statement: Written informed consent has been obtained from the patient(s) to publish this paper.

Data Availability Statement: The data presented in this study are available upon request from Jolanta Flieger.

Conflicts of Interest: The authors declare no conflict of interest.

\section{References}

1. Ferrea, S.; Winterer, G. Neuroprotective and neurotoxic effects of nicotine. Pharmacopsychiatry 2009, 42, 255-265. [CrossRef]

2. Mayer, B. How much nicotine kills a human? Tracing back the generally accepted lethal dose to dubious self-experiments in the nineteenth century. Arch. Toxicol. 2014, 88, 5-7. [CrossRef]

3. Available online: https://www.rch.org.au/clinicalguide/guideline_index/Nicotine_Poisoning/ (accessed on 31 January 2019).

4. Rodgman, A.; Perfetti, T.A. The Chemical Components of Tobacco and Tobacco Smoke, 2nd ed.; CRC Press, Taylor \& Francis Group: Boca Raton, FL, USA, 2013.

5. Jemal, A.; Thun, M.J.; Ries, L.A.; Howe, H.L.; Weir, H.K.; Center, M.M.; Ward, E.; Wu, X.C.; Eheman, C.; Anderson, R.; et al. Annual report to the nation on the status of cancer, 1975-2005, featuring trends in lung cancer, tobacco use, and tobacco control. J. Natl. Cancer Inst. 2008, 100, 1672-1694. [CrossRef] [PubMed]

6. WHO Report on the Global Tobacco Epidemic 2009: Implementing Smoke-Free Environments; World Health Organization: Geneva, Switzerland, 2009.

7. WHO Report on the Global Tobacco Epidemic 2021: Addressing New and Emerging Products; World Health Organization: Geneva, Switzerland, 2021.

8. Benowitz, N.L. Pharmacology of nicotine: Addiction, smoking-induced disease, and therapeutics. Annu. Rev. Pharmacol. Toxicol. 2009, 49, 57-71. [CrossRef] [PubMed]

9. Benowitz, N.L.; Hukkanen, J.; Jacob, P., III. Nicotine chemistry, metabolism, kinetics and biomarkers. Handb. Exp. Pharmacol. 2009, 192, 29-60. [CrossRef]

10. Hukkanen, J.; Jacob, P., III; Benowitz, N.L. Metabolism and disposition kinetics of nicotine. Pharmacol. Rev. 2005, 57, 79-115. [CrossRef] [PubMed]

11. Yildiz, D. Nicotine, its metabolism and an overview of its biological effects. Toxicon 2004, 43, 619-632. [CrossRef] [PubMed]

12. Tanner, J.A.; Chenoweth, M.J.; Tyndale, R.F. Pharmacogenetics of nicotine and associated smoking behaviors. Curr. Top. Behav. Neurosci. 2015, 23, 37-86. [CrossRef] [PubMed]

13. Benowitz, N.L. Cotinine as a biomarker of environmental tobacco smoke exposure. Epidemiol. Rev. 1996, 18, 188-204. [CrossRef] [PubMed]

14. Seccareccia, F.; Zuccaro, P.; Pacifici, R.; Meli, P.; Pannozzo, F.; Freeman, K.M.; Santaquilani, A.; Giampaoli, S. Serum cotinine as a marker of environmental tobacco smoke exposure in epidemiological studies: The experience of the MATISS project. Eur. J. Epidemiol. 2003, 18, 487-492. [CrossRef]

15. Murphy, S.E.; Johnson, L.M.; Pullo, D.A. Characterization of multiple products of cytochrome P450 2A6-catalyzed cotinine metabolism. Chem. Res. Toxicol. 1999, 12, 639-645. [CrossRef]

16. Flieger, J.; Kawka, J.; Tatarczak-Michalewska, M. Levels of the Thiocyanate in the Saliva of Tobacco Smokers in Comparison to e-Cigarette Smokers and Nonsmokers Measured by HPLC on a Phosphatidylcholine Column. Molecules 2019, 24, 3790. [CrossRef]

17. Haley, N.J.; Hoffmann, D. Analysis for nicotine and cotinine in hair to determine cigarette smoker status. Clin. Chem. 1985, 31, 1598-1600. [CrossRef] 
18. Machacek, D.A.; Jiang, N.S. Quantification of cotinine in plasma and saliva by liquid chromatography. Clin. Chem. 1986, 32, 979-982. [CrossRef]

19. Wall, M.A.; Johnson, J.; Jacob, P.; Benowitz, N.L. Cotinine in the serum, saliva, and urine of nonsmokers, passive smokers, and active smokers. Am. J. Public Health 1988, 78, 699-701. [CrossRef]

20. Park, S.; Lee, D.H.; Park, J.G.; Lee, Y.T.; Chung, J. A sensitive enzyme immunoassay for measuring cotinine in passive smokers. Clin. Chim. Acta 2010, 411, 1238-1242. [CrossRef]

21. Zuccaro, P.; Altieri, I.; Rosa, M.; Passa, A.R.; Pichini, S.; Ricciarello, G.; Pacifici, R. Determination of nicotine and four metabolites in the serum of smokers by high-performance liquid chromatography with ultraviolet detection. J. Chromatogr. 1993, 621, 257-261. [CrossRef]

22. Yasuda, M.; Ota, T.; Morikawa, A.; Mawatari, K.; Fukuuchi, T.; Yamaoka, N.; Kaneko, K.; Nakagomi, K. Simultaneous determination of nicotine and cotinine in serum using high-performance liquid chromatography with fluorometric detection and postcolumn UV-photoirradiation system. J. Chromatogr. B Analyt. Technol. Biomed. Life Sci. 2013, 934, 41-45. [CrossRef] [PubMed]

23. Avagyan, R.; Spasova, M.; Lindholm, J. Determination of Nicotine-Related Impurities in Nicotine Pouches and Tobacco-Containing Products by Liquid Chromatography-Tandem Mass Spectrometry. Separations 2021, 8, 77. [CrossRef]

24. Abu-Awwad, A.; Arafat, T.; Schmitz, O.J. Simultaneous determination of nicotine, cotinine, and nicotine N-oxide in human plasma, semen, and sperm by LC-Orbitrap MS. Anal. Bioanal. Chem. 2016, 408, 6473-6481. [CrossRef] [PubMed]

25. Baumann, F.; Regenthal, R.; Burgos-Guerrero, I.L.; Hegerl, U.; Preiss, R. Determination of nicotine and cotinine in human serum by means of LC/MS. J. Chromatogr. B Analyt. Technol. Biomed. Life Sci. 2010, 878, 107-111. [CrossRef] [PubMed]

26. Jacob, P., III; Yu, L.; Duan, M.; Ramos, L.; Yturralde, O.; Benowitz, N.L. Determination of the nicotine metabolites cotinine and trans-3'-hydroxycotinine in biologic fluids of smokers and non-smokers using liquid chromatography-tandem mass spectrometry: Biomarkers for tobacco smoke exposure and for phenotyping cytochrome P450 2A6 activity. J. Chromatogr. B Analyt. Technol. Biomed. Life Sci. 2011, 879, 267-276. [CrossRef]

27. Gabr, R.Q.; Elsherbiny, M.E.; Somayaji, V.; Pollak, P.T.; Brocks, D.R. A liquid chromatography-mass spectrometry method for nicotine and cotinine; utility in screening tobacco exposure in patients taking amiodarone. Biomed. Chromatogr. 2011, 25, 1124-1131. [CrossRef]

28. Shakleya, D.M.; Huestis, M.A. Optimization and validation of a liquid chromatography-tandem mass spectrometry method for the simultaneous quantification of nicotine, cotinine, trans-3'-hydroxycotinine and norcotinine in human oral fluid. Anal. Bioanal. Chem. 2009, 395, 2349-2357. [CrossRef] [PubMed]

29. Dobrinas, M.; Choong, E.; Noetzli, M.; Cornuz, J.; Ansermot, N.; Eap, C.B. Quantification of nicotine, cotinine, trans-3'hydroxycotinine and varenicline in human plasma by a sensitive and specific UPLC-tandem mass-spectrometry procedure for a clinical study on smoking cessation. J. Chromatogr. B Analyt. Technol. Biomed. Life Sci. 2011, 879, 3574-3582. [CrossRef] [PubMed]

30. Scheidweiler, K.B.; Shakleya, D.M.; Huestis, M.A. Simultaneous quantification of nicotine, cotinine, trans-3'-hydroxycotinine, norcotinine and mecamylamine in human urine by liquid chromatography-tandem mass spectrometry. Clin. Chim. Acta 2012, 413, 978-984. [CrossRef] [PubMed]

31. Chazeron, I.; Daval, S.; Ughetto, S.; Richard, D.; Nicolay, A.; Lemery, D.; Llorca, P.M.; Coudoré, F. GC-MS determined cotinine in an epidemiological study on smoking status at delivery. Pulm. Pharmacol. Ther. 2008, 21, 485-488. [CrossRef]

32. Man, C.N.; Gam, L.-H.; Ismail, S.; Lajis, R.; Awang, R. Simple, rapid and sensitive assay method for simultaneous quantification of urinary nicotine and cotinine using gas chromatography-mass spectrometry. J. Chromatogr. B Analyt. Technol. Biomed. Life Sci. 2006, 844, 322-327. [CrossRef]

33. Yue, B.; Kushnir, M.M.; Urry, F.M.; Rockwood, A.L. Quantitation of nicotine, its metabolites, and other related alkaloids in urine, serum, and plasma using LC-MS-MS. Methods Mol. Biol. 2010, 603, 389-398. [CrossRef]

34. Xu, X.; Iba, M.M.; Weisel, C.P. Simultaneous and sensitive measurement of anabasine, nicotine, and nicotine metabolites in human urine by liquid chromatography-tandem mass spectrometry. Clin. Chem. 2004, 50, 2323-2330. [CrossRef] [PubMed]

35. von Weymarn, L.B.; Thomson, N.M.; Donny, E.C.; Hatsukami, D.K.; Murphy, S.E. Quantitation of the Minor Tobacco Alkaloids Nornicotine, Anatabine, and Anabasine in Smokers' Urine by High Throughput Liquid Chromatography-Mass Spectrometry. Chem. Res. Toxicol. 2016, 29, 390-397. [CrossRef] [PubMed]

36. Taghavi, T.; Novalen, M.; Lerman, C.; George, T.P.; Tyndale, R.F. A Comparison of Direct and Indirect Analytical Approaches to Measuring Total Nicotine Equivalents in Urine. Cancer Epidemiol. Biomark. Prev. 2018, 27, 882-891. [CrossRef]

37. Shaik, F.B.; Nagajothi, G.; Swarnalatha, K.; Kumar, C.S.; Maddu, N. Quantification of Nicotine and Cotinine in Plasma, Saliva, and Urine by HPLC Method in Chewing Tobacco Users. Asian Pac. J. Cancer Prev. 2019, 20, 3617-3623. [CrossRef] [PubMed]

38. Miller, E.I.; Norris, H.R.; Rollins, D.E.; Tiffany, S.T.; Wilkins, D.G. A novel validated procedure for the determination of nicotine, eight nicotine metabolites and two minor tobacco alkaloids in human plasma or urine by solid-phase extraction coupled with liquid chromatography-electrospray ionization-tandem mass spectrometry. J. Chromatogr. B 2010, 878, 725-737. [CrossRef] [PubMed]

39. Meger, M.; Meger-Kossien, I.; Schuler-Metz, A.; Janket, D.; Scherer, G. Simultaneous determination of nicotine and eight nicotine metabolites in urine of smokers using liquid chromatography-tandem mass spectrometry. J. Chromatogr. B 2002, 778, $251-261$. [CrossRef] 
40. McGuffey, J.E.; Wei, B.; Bernert, J.T.; Morrow, J.C.; Xia, B.; Wang, L.; Blount, B.C. Validation of a LC-MS/MS method for quantifying urinary nicotine, six nicotine metabolites and the minor tobacco alkaloids-Anatabine and anabasine-In smokers' urine. PLOS ONE 2014, 9, e101816. [CrossRef] [PubMed]

41. Marclay, F.; Saugy, M. Determination of nicotine and nicotine metabolites in urine by hydrophilic interaction chromatographytandem mass spectrometry: Potential use of smokeless tobacco products by ice hockey players. J. Chromatogr. A 2010, 1217, 7528-7538. [CrossRef]

42. Kataoka, H.; Inoue, R.; Yagi, K.; Saito, K. Determination of nicotine, cotinine, and related alkaloids in human urine and saliva by automated in-tube solid-phase microextraction coupled with liquid chromatography-mass spectrometry. J. Pharm. Biomed. Anal. 2009, 49, 108-114. [CrossRef] [PubMed]

43. Heavner, D.L.; Richardson, J.D.; Morgan, W.T.; Ogden, M.W. Validation and application of a method for the determination of nicotine and five major metabolites in smokers' urine by solid-phase extraction and liquid chromatography-tandem mass spectrometry. Biomed. Chromatogr. 2005, 19, 312-328. [CrossRef]

44. Wei, B.; Feng, J.; Rehmani, I.J.; Miller, S.; McGuffey, J.E.; Blount, B.C.; Wang, L. A high-throughput robotic sample preparation system and HPLC-MS/MS for measuring urinary anatabine, anabasine, nicotine and major nicotine metabolites. Clin. Chim. Acta 2014, 436, 290-297. [CrossRef] [PubMed]

45. Yuan, C.; Kosewick, J.; Wang, S. A simple, fast, and sensitive method for the measurement of serum nicotine, cotinine, and nornicotine by LC-MS/MS. J. Sep. Sci. 2013, 36, 2394-2400. [CrossRef] [PubMed]

46. Shu, I.; Wang, P. Simultaneous serum nicotine, cotinine, and trans-3'-hydroxycotinine quantitation with minimal sample volume for tobacco exposure status of solid organ transplant patients. J. Chromatogr. B 2013, 928, 139-145. [CrossRef]

47. Byrd, G.D.; Davis, R.A.; Ogden, M.W. A rapid LC-MS-MS method for the determination of nicotine and cotinine in serum and saliva samples from smokers: Validation and comparison with a radioimmunoassay method. J. Chromatogr. Sci. 2005, 43, 133-140. [CrossRef] [PubMed]

48. Abdallah, I.A.; Hammell, D.C.; Stinchcomb, A.L.; Hassan, H.E. A fully validated LC-MS/MS method for simultaneous determination of nicotine and its metabolite cotinine in human serum and its application to a pharmacokinetic study after using nicotine transdermal delivery systems with standard heat application in adult smokers. J. Chromatogr. B 2016, 1020, 67-77. [CrossRef]

49. Tzatzarakis, M.N.; Vardavas, C.I.; Terzi, I.; Kavalakis, M.; Kokkinakis, M.; Liesivuori, J.; Tsatsakis, A.M. Hair nicotine/cotinine concentrations as a method of monitoring exposure to tobacco smoke among infants and adults. Hum. Exp. Toxicol. 2012, 31, 258-265. [CrossRef]

50. Miller, E.I.; Murray, G.J.; Rollins, D.E.; Tiffany, S.T.; Wilkins, D.G. Validation of a liquid chromatography-tandem mass spectrometry method for the detection of nicotine biomarkers in hair and an evaluation of wash procedures for removal of environmental nicotine. J. Anal. Toxicol. 2011, 35, 321-332. [CrossRef]

51. Kim, J.; Cho, H.D.; Suh, J.H.; Lee, J.Y.; Lee, E.; Jin, C.H.; Wang, Y.; Cha, S.; Im, H.; Han, S.B. Analysis of Nicotine Metabolites in Hair and Nails Using QuEChERS Method Followed by Liquid Chromatography-Tandem Mass Spectrometry. Molecules 2020, 25, 1763. [CrossRef] [PubMed]

52. Inukai, T.; Kaji, S.; Kataoka, H. Analysis of nicotine and cotinine in hair by on-line in-tube solid-phase microextraction coupled with liquid chromatography-tandem mass spectrometry as biomarkers of exposure to tobacco smoke. J. Pharm. Biomed. Anal. 2018, 156, 272-277. [CrossRef]

53. Chetiyanukornkul, T.; Toriba, A.; Kizu, R.; Kimura, K.; Hayakawa, K. Hair analysis of nicotine and cotinine for evaluating tobacco smoke exposure by liquid chromatography-mass spectrometry. Biomed. Chromatogr. 2004, 18, 655-661. [CrossRef]

54. Xia, B.; McGuffey, J.; Xia, Y.; Guillot, T.; McGahee, E.; Wang, L.; Blount, B. Sensitive, Rapid and High Throughput Measurement of Nicotine in Human Serum by Automation and Liquid Chromatography-Atmospheric Pressure Ionization Tandem Mass Spectrometry; American Chemical Society: Washington, DC, USA, 2017.

55. Xia, B.; Blount, B.C.; Wang, L. Sensitive Quantification of Nicotine in Bronchoalveolar Lavage Fluid by Acetone Precipitation Combined with Isotope-Dilution Liquid Chromatography-Tandem Mass Spectrometry. ACS Omega 2021, 6, 13962-13969. [CrossRef] [PubMed]

56. Flieger, J. The effect of chaotropic mobile phase additives on the separation of selected alkaloids in reversed-phase highperformance liquid chromatography. J. Chromatogr. A 2006, 1113, 37-44. [CrossRef] [PubMed]

57. Flieger, J.; Czajkowska-Żelazko, A. Comparison of chaotropic salt and ionic liquid as mobile phase additives in reversed-phase high-performance liquid chromatography of biogenic amines. J. Sep. Sci. 2011, 34, 733-739. [CrossRef] [PubMed]

58. Flieger, J.; Siwek, A.; Pizoń, M. Usefulness of chaotropic salt additive in RP-HPLC of organic nonionized compounds. J. Sep. Sci. 2013, 36, 469-476. [CrossRef]

59. Clayton, P.; Vas, C.; Bui, T.; Drake, A.; Mcadam, K. Spectroscopic investigations into the acid-base properties of nicotine at different temperatures. Anal. Methods 2013, 5, 81-88. [CrossRef]

60. Mattes, W.; Yang, X.; Orr, M.S.; Richter, P.; Mendrick, D.L. Biomarkers of Tobacco Smoke Exposure. Adv. Clin. Chem. 2014, 67, 1-45. [CrossRef] [PubMed]

61. Bansal, S.; DeStefano, A. Key elements of bioanalytical method validation for small molecules. AAPS J. 2007, 9, E109-E114. [CrossRef] 
62. Viswanathan, C.T.; Bansal, S.; Booth, B.; DeStefano, A.J.; Rose, M.J.; Sailstad, J.; Shah, V.P.; Skelly, J.P.; Swann, P.G.; Weiner, R. Quantitative bioanalytical methods validation and implementation: Best practices for chromatographic and ligand binding assays. Pharm. Res. 2007, 24, 1962-1973. [CrossRef]

63. Kim, S. Overview of Cotinine Cutoff Values for Smoking Status Classification. Int. J. Environ. Res. Public Health 2016, 13, 1236. [CrossRef] [PubMed] 